\title{
COMPARING THE PROTECTIVE PEER RELATIONSHIPS OF STUDENTS WITH AND WITHOUT DISABILITIES
}

\author{
Dorothy C. Pendleton
}

A thesis submitted to the faculty of the University of North Carolina at Chapel Hill in partial fulfillment of the requirements for the degree of Master of Arts in the School of Education (School Psychology).

Chapel Hill

2008

Approved by:

Chair: Samuel Song, Ph.D.

Reader: Rune Simeonsson, Ph.D.

Reader: Steve Knotek, Ph.D. 


\begin{abstract}
DOROTHY PENDLETON: Comparing the Protective Peer Relationships of Students With and Without Disabilities

(Under the direction of Samuel Song)

The purpose of this study was to compare the levels of protective peer relationships

experienced by $3^{\text {rd }}$ to $5^{\text {th }}$ grade students, with and without disabilities. The participants

completed a self-report measure of protective peer relationships and school records were reviewed for gender and disability status. A one-way analysis of variance (ANOVA) was conducted to evaluate the relation between disability status and levels of protective peer relationships. To compare gender differences and disability status in relation to levels of protective peer relationships, a two-way ANOVA was conducted. Findings did not support a significant relation between disability status and levels of protective peer relationships. There was a significant main effect for gender, as well as a significant interaction between gender and disability status. Results suggest that girls with disabilities are more likely to experience protective peer relationships than boys with disabilities. Implications of these findings are discussed.
\end{abstract}




\section{ACKNOWLEDGEMENTS}

I would like to thank my advisor, Dr. Sam Song, for his mentorship and guidance throughout this endeavor. I am appreciative of Drs. Rune Simeonsson and Steve Knotek for their support of and contributions to this project. I would also like to thank my parents, Wally and

Kathy Pendleton, for their never-ending support and encouragement and for always believing in me. 


\section{TABLE OF CONTENTS}

LIST OF TABLES....... .vi

\section{Chapter}

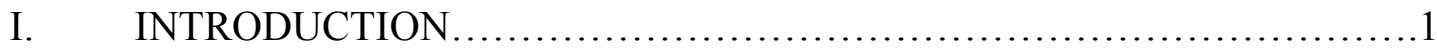

II. REVIEW OF LITERATURE ............................................

Importance of Peer Relationships and Bullying............................4

Developmental Trends of Peer Attitudes Toward Students with

Disabilities.................................................................

Specific Disabilities and Victimization.................................

Students with Disabilities' Perceptions of Their

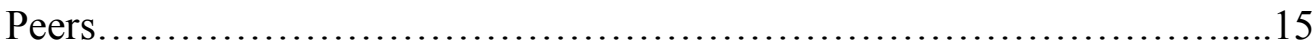

III. SUMMARY, PURPOSE, AND RESEARCH QUESTIONS.......................16

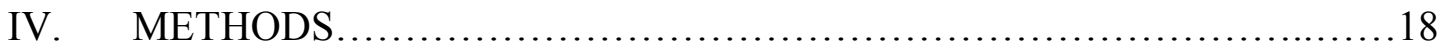

Description of Larger Study......................................... 18

Procedures........................................................... 18

Participants.......................................................... 19

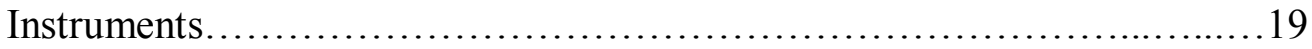

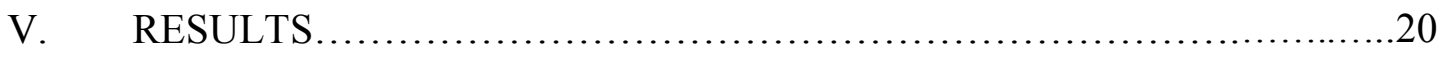

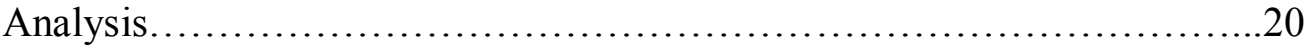

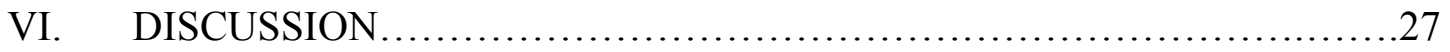

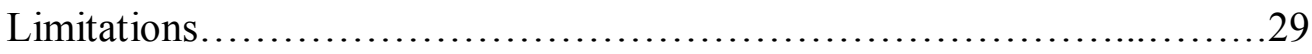

Future Research...................................................... 31 


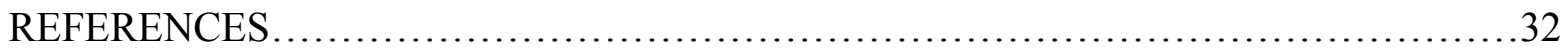




\section{LIST OF TABLES}

Table

1. Means and standard deviations for protective peer relationships as a function of gender and disability status

2. Means and standard deviations for protective peer relationships as a function of grade level, gender, and disability status.........................22

3. One-way ANOVA results for comparing protective peer relationships among students with and without disabilities ................................. 24

4. Two-way ANOVA results for comparing protective peer relationships based on gender and disability status .25 


\section{CHAPTER 1}

\section{COMPARING THE PROTECTIVE PEER RELATIONSHIPS OF STUDENTS WITH AND WITHOUT DISABILITIES}

The number of students receiving special educational services, i.e., services under the Exceptional Children classification, has increased each decade. From 1990 to 2002, there was a $34 \%$ increase in the number of students receiving special education services (National Center for Education Statistics [NCES], 2003). Passed in October 1990, the Individuals with Disabilities Education Act (IDEA) introduced new rules and regulations concerning the education of children with special needs. IDEA was most recently reauthorized in 2004, assuming the name of Individuals with Disabilities Education Improvement Act (IDEIA) of 2004. Section 612(a)(5) of IDEIA states that children with disabilities must be educated in the least restrictive environment. Specifically, IDEIA maintains that:

To the maximum extent appropriate, children with disabilities, including children in public or private institutions or other care facilities, are educated with children who are not disabled, and special classes, separate schooling, or other removal of children with disabilities from the regular educational environment occurs only when the nature or severity of the disability of a child is such that education in regular classes with the use of supplementary aids and services cannot be achieved satisfactorily. (IDEIA, 20 U.S.C. $§ 1412(B)(612)(a)(5), 2004)$

It is assumed that there are many benefits of educating students with special needs in

the LRE, such as increased motivation, greater self-esteem, better communication and socialization skills, and enhanced academic achievement (Least Restrictive Environment Coalition, n.d.). Also, typically developing peers may display more age-appropriate and positive levels of cognitive, communication, and social skills than would normally be found 
in a self-contained setting (Odom, Zercher, Li, Marquart, Sandall, Brown, 2004). Because of this, many children with special needs now spend at least part of their school day in regular education classes or in an environment with typically developing peers. Still, there may also be some unintended negative side effects, such as bullying, as a result of having children with special needs interact more frequently with typically developing peers.

A 2001 study conducted by the National Institute of Child Heath and Human Development concluded that approximately 3 in 10 children are affected by bullying (Flynt $\&$ Morton, 2004). Although specific prevalence rates are not available, students with disabilities are more likely to be bullied than non-disabled students (Thompson, Whitney, and Smith, 1994). Because children with disabilities are more likely to be bullied, they may be even more susceptible to bullying when they participate in the least restrictive environment, such as a regular education classroom. Specifically, children with mental retardation appear to be at the greatest risk for bullying since they often have low self-esteem and may be unable to perceive a variety of social cues, including awareness of a dangerous or threatening situation that may be occurring (Flynt \& Morton, 2004). Additionally, children with motor skills deficits and physical disabilities may be easy targets for victimization due to the noticeable aspects of their disability (Flynt \& Morton, 2004).

At the present time, little is known about how disability status relates to bullying. While previous research has focused on specific disability subgroups (i.e., autism, mental retardation, learning disability, etc), there remains a lack of research pertaining to disability status in general and its relation to bullying. It is also important to consider the relation between gender and level of victimization experienced by students with disabilities. Males, 
in particular, receive special education services in higher numbers than females, as they make up almost two-thirds of the special education population (U.S. Department of Education, 2005). Because males are more likely to receive special education services (U.S. Department of Education, 2005), they may be more vulnerable to bullying and victimization by peers. However, the possibility exists that females receiving services are more likely to be bullied, victimized, and/or ostracized, as they are less likely to have same sex peers who have similar disabilities, since females only account for one-third of the special education population (U.S. Department of Education, 2005). Certainly, the quality of children's peer relationships (i.e., protection from bullying), especially those with special needs, could play a major role in the severity and/or frequency of bullying experienced in the school environment.

The purpose of this research study is to ascertain the differences in protective peer relationships experienced by children with and without disabilities. For this study, protective peer relationships will be broadly defined as (a) having peers who will stick up for a fellow student if he or she is being bullied and (b) having peers who will attempt to prevent bullying from occurring in the first place (Song \& Stoiber, in press).

This paper will review extant literature pertaining to peer relationships, bullying, and attitudes of, and toward, students with disabilities. The overarching goal of this research is to determine whether or not students with disabilities report fewer, or possibly greater, levels of protective peer relationships compared to non-disabled students. Another goal of this research is to assess gender differences in the level of protective peer relationships reported by students with disabilities. Conclusions and ideas for future research will also be discussed. 


\section{CHAPTER 2}

\section{REVIEW OF LITERATURE}

The review of literature will cover four main areas. First, literature pertaining to the importance of peer relationships and bullying during childhood and adolescence will be

discussed. Second, research investigating the developmental trends of peer relationships of students with disabilities will be appraised. Specifically, literature reviewed will include attitudes of non-disabled students toward students with disabilities and vice versa. Third, literature pertaining to bullying and students with disabilities will be reviewed. Finally, the perspective of students with disabilities will be taken into account; more specifically, who do students with disabilities look up to or emulate?

\section{Importance of Peer Relationships and Bullying}

While peer relationships are an important and significant part of childhood, the focus of this area of the literature review will be on friendships, simply because there is a greater availability of empirical literature on friendships compared to the broader notion of peer relationships. Friendships during childhood and adolescence serve many important purposes. Rubin, Dwyer, Booth-LaForce, Kim, Burgess, and Rose-Krasnor (2004) found that in early adolescence (i.e., fifth grade), perceptions of friendship quality were linked to higher selfesteem, increased perceptions of social competence, and fewer internalizing problems. Through their friendships, children are also able to develop important social skills while 
simultaneously boosting levels of self-esteem (Hodges et al., 1999). Further, childhood friendships also prepare children and adolescents for relationships later in life, including dating (Hodges et al., 1999). Additionally, Hodges and colleagues speculated that having high-quality friendships might reduce overall levels of internalizing and externalizing problems because such problems could ultimately destroy the friendship. Other important benefits of friendships during childhood and adolescence include successful school adjustment, social participation in peer groups, increased academic performance, and longterm social adjustment (Odom et al., 2006). Notably, when children experience peer rejection at a young age, there is a stronger chance for poor outcomes in adulthood (Odom et al., 2006).

Friendships can also serve as a buffer against bullying and peer victimization. There has been some debate amongst researchers as to whether friendship quality or friendship quantity is more likely to prevent bullying and victimization. Both individual factors, such as social skills, and social factors, including peer acceptance, appear to influence the likelihood of becoming a victim (Fox \& Boulton, 2006). Through the use of a peer nomination inventory, Fox and Boulton (2006) discovered that social skills problems (i.e., looks upset when picked on; looks scared often; looks like a weak person) tended to result in higher levels of victimization for elementary-age children. However, the total number of friends and the overall peer acceptance of the best friend appeared to serve as moderators, resulting in lower rates of victimization. These researchers ultimately found that the total number of friends was the most significant influence on becoming a victim. This differs from the notion that perhaps the quality, rather than quantity, of friendships is more important in preventing 
victimization. Other research (e.g., Vaughn, Elbaum, Schumm, Hughes, 1998) has suggested that simply having one reciprocal friendship — defined as a friendship that is acknowledged by both parties—can serve as a significant buffer against both peer rejection and victimization.

Hodges, Boivin, Vitaro, and Bukowski (1999) found that fifth graders who reported having high-quality friendships were more likely to be better adjusted (i.e., socially, academically, etc.) than students who experienced lower-quality friendships. Further, when females reported high-quality friendships, they were less likely to experience peer rejection and victimization. Interestingly, the same was not true for males, though the researchers were unsure why this was the case. The findings of Rubin et al. (2004) support previous research, suggesting that high-quality friendships can serve as a buffer against peer victimization and bullying (Hodges et al., 1999).

One aspect of peer relations that deters bullying has been referred to as protective peer relationships in which peers protect one another from bullying (Song \& Stoiber, in press). Being protected by peers from bullying has been shown to be negatively related to being bullied in upper elementary (Song, Doll, Swearer, \& Johnsen, 2005). However, no research has examined protective peer relationships among children with special needs.

Based on the literature reviewed, friendships appear to be an important predictor of a child's future successes. Notably, most of this prior research has focused on the importance of friendships for typically developing students. There appears to be a lack of research exploring the importance of peer relationships and protective peer relationships in particular in students with disabilities. Since students with disabilities are more likely to become 
victims of bullying (Flynt \& Morton, 2004), there is a strong need for future research to focus specifically on the importance of protective peer relationships for students with disabilities.

Developmental Trends of Peer Attitudes Toward Students with Disabilities In terms of developmental trends, the attitudes of non-disabled students toward their peers with disabilities seem to change throughout the progression of the elementary, middle, and high school years. Research on kindergarten-age children (Dyson, 2005), conducted through interviewing, revealed that most children in this young age range had positive views of their disabled peers. Although $83 \%$ of these children reported having positive or empathetic feelings toward their peers with disabilities, less than half reported having a friend with a disability, suggesting that children with disabilities likely do not have many close or supportive friends in the general education classroom (Dyson, 2005). And, while younger children seem to possess an awareness of what a disability is, they tend to associate disabilities with physical appearance only (Dyson, 2005). Tamm and Prellwitz (2001) found that students in first grade believed that children with mobility disabilities who were in wheelchairs were able to eventually recover, as they believed the disability was only temporary; on the other hand, children in third grade were more aware of the permanent implications of a disability. Certainly, it would be informative if future research examined the thought processes and/or social experiences that contribute to this major shift in children's approach to disabilities, since overall awareness seems to change drastically over a short time span.

As children with disabilities age, they will certainly encounter more adversity in the 
classroom and school environment as peers became increasingly cognizant of individual differences, whether they are physical, emotional, educational, etc. Longitudinal research suggests that a smaller number of reciprocal peer relationships exist for children with disabilities when they are in upper elementary grades in comparison to kindergarten or first grade (Hall \& McGregor, 2000). Older children with disabilities appear to have more difficulty establishing and maintaining friendships with non-disabled peers than younger children with disabilities (Hall \& McGregor, 2000). This may, in part, be due to the fact that they spend less time participating in large-group activities and spend more time in isolation, either by choice or as a consequence of peer rejection. School-aged children with mild disabilities often have social skills deficits and, interestingly, are more likely to associate with aggressive classmates and classmates who have poor interpersonal skills (Rodkin, Farmer, Van Acker, Pearl, Thompson, Fedora, 2006). These skills deficits certainly increase the potential of peer rejection and perhaps even victimization.

Age differences are also found in regards to extracurricular activity taking place in the school setting. For younger children, play time and recess are times when students with disabilities really "stand out," as they often tire easily or are simply unable to participate, forcing them to stand on the sidelines (Tamm \& Prellwitz, 2001). And, while younger children typically tend to choose playmates of the same sex, non-disabled children are also more likely to choose non-disabled playmates, resulting in children with disabilities being left out or ostracized (Tamm \& Prellwitz, 2001). Interestingly, high-school-age adolescents with restricted mobility disabilities reported that in order to establish and maintain friendships, they often chose to play younger children, as the younger children were often 
more accepting of physical disabilities than their same age peers, especially during games and activities requiring movement (Skar, 2003).

Overall, information gleaned from literature pertaining to developmental trends in peer attitudes revealed that students with disabilities often experience fewer positive peer relationships as they progress through elementary school. In the early years, students with disabilities are more accepted by their peers (Dyson, 2005). Hall and McGregor (2000) found that in the upper elementary years, students with disabilities are likely to experience fewer peer relationships than they did in the early elementary years. Dramatic changes in peer attitudes appear to occur in a span of four to five years. This necessitates the importance of implementing intervention programs that encourage the acceptance of students with disabilities during the early elementary years, perhaps as early as kindergarten.

\section{Specific Disabilities and Victimization}

While the type of disability may predict the particular risk for victimization, some research suggests that all students with disabilities who are in a mainstreamed schooling environment are at a greater risk for being bullied in comparison to peers without disabilities (Cooney, Jahoda, Gumley, Knott, 2006). The following literature review encompasses levels of victimization reported by students with disabilities.

\section{Emotional Disabilities}

When focusing on specific disabilities, high school students with serious emotional disturbance (SED) disability status are at a greatly increased risk for victimization (Doren, Bullis, and Benz, 1996). Students with SED who were low on measures of personal and 
social achievement were approximately twenty times more likely to experience victimization in school in comparison to their non-disabled peers, while non-disabled students who were low on social and personal achievement, but not classified as having SED, were only two times more likely to experience victimization (Doren et al., 1996).

\section{Physical Disabilities}

Mainstreamed students with hemiplegia, ages nine and ten, were compared to their non-disabled peers on different sociometric measures, such as popularity and friendship (Yude, Goodman, and McConachie, 1998). Compared with non-disabled students, those with hemiplegia were significantly more likely to be identified as a member of the rejected group and were underrepresented in the popular group; additionally, they experienced fewer reciprocated friendships. When looking at levels of victimization, $45 \%$ of adolescents with hemiplegia were victimized in comparison to only $13 \%$ of their non-disabled peers (Yude et al., 1998). Many of these disabled students blamed their peer difficulties on their physical limitations and attributed their victimization to the visible aspects of their disability (i.e., a limp, braces, special shoes).

Other research (Nadeau \& Tessier, 2006) investigated the social experiences of tenyear-old children with cerebral palsy, diagnosed as having hemiplegia or diplegia, who were mainstreamed. Interestingly, several gender differences were very apparent in regards to social environment. Females with cerebral palsy, regardless of type of disability classification, were less accepted than non-disabled females, had fewer reciprocated friendships than non-disabled females, and possessed fewer leadership behaviors and more isolation behaviors than non-disabled females (Nadeau \& Tessier, 2006). There were no 
significant differences in these areas when comparing males with cerebral palsy to nondisabled males. All students with cerebral palsy, regardless of gender, were viewed by their peers as experiencing greater levels of verbal victimization than non-disabled peers. Interestingly, children with hemiplegia, and not diplegia, were more likely to be physically victimized (Nadeau \& Tessier, 2006).

\section{Autism}

Children with autism, a disability characterized by social and communication deficits, certainly seem to be at-risk for rejection by non-disabled peers in a general education environment. Because children with autism tend to have very low academic skills, the reasoning behind inclusion with non-disabled peers is often solely to enhance their social experiences (Boutot \& Bryant, 2005). Three different measures of social integration (social preference, social impact, and social network affiliation) in regards to children with autism were investigated by Boutot and Bryant (2005), mainly through the use of peer nominations in conjunction with an autism rating scale, which assessed the severity of each child's characteristic behavior. Findings indicated that no significant differences existed between students with autism and non-disabled students on the constructs of social preference, social impact, or social network affiliation (Boutot \& Bryant, 2005). Thus, the children with autism were just as likely as their non-disabled peers to be included in a variety of activities, were equally visible in the classroom, and were just as likely to be considered a member of a specific social group (Boutot \& Bryant, 2005).

Boutot and Bryant's research conflicts with the findings of Orsmond, Krauss, and Seltzer (2004), who investigated peer relationships in both adolescents and adults with 
autism. In their study, almost half of the sample reported having no reciprocal friendships outside of pre-arranged settings, such as work and support groups. Adolescents with higher functioning autism were more likely to have friendships than severely impaired autistic adolescents, but the same did not hold true for adults with higher functioning forms of autism (Orsmond et al., 2004). Further, Orsmond and colleagues (2004) found that educating students with autism in a mainstreamed versus self-contained environment did not result in a greater number of peer relationships. Ultimately, for children with autism, overall levels of social skills seem to predict the total number of peer relationships (Orsmond et al., 2004).

\section{Intellectual Disabilities}

Adolescents, ranging in age from 15 to 17 , with mild to moderate intellectual disabilities, who were either mainstreamed or educated in a segregated school, completed self-report measures in an effort to assess their perceptions of stigmatized treatment in the school environment (Cooney et al., 2006). Mainstreamed students with intellectual disabilities were more likely to receive stigmatized treatment by their non-disabled peers, such as name-calling, physical harassment, and being ignored by other students. On the other hand, students from the segregated school reported no instances of being called names or being physically harassed during school (Cooney et al., 2006).

\section{Mild/High-Frequency Disabilities}

Regarding high-frequency disabilities, research on children with learning disabilities (Kaukiainen, Salmivalli, Lagerspetz, Tamminen, Vauras, et al., 2002) indicated that students with learning disabilities are at a greater risk of being victimized, but that they may also bully other students at a greater rate than students without learning disabilities. Children with 
learning disabilities may fall into the classification of bully-victim more easily than nonlearning disabled students since they often have impairments in communication and tend to lack developmentally appropriate social skills (Kaukiainen et al., 2002). Still, Norwich and Kelly (2004) found that approximately $83 \%$ of students with learning disabilities reported being bullied - physically, verbally, or in a teasing manner. Almost half of the students surveyed reported that the bullying they received was due to their learning disability. Specifically, females who were mainstreamed reported higher levels of victimization than females who attended a separate setting school (Norwich \& Kelly, 2004). Mainstreamed males, on the other hand, reported fewer instances of bullying than males attending a separate school (Norwich \& Kelly, 2004). Regardless of gender, students with learning disabilities who attended a separate school still reported being victimized by peers attending regular schools and neighborhood peers. Victimization was found to be unlikely to occur at the hands of other students enrolled in the separate setting schools (Norwich \& Kelly, 2004).

Other research (e.g., Savage, 2005) exploring the effect of mainstreaming students with special needs has suggested that students who are segregated from their non-disabled peers are more likely to experience bullying. Seventh grade students who received special education services for speech and language impairments in a resource classroom rated themselves as being three times more likely to experience bullying than their mainstreamed peers (Savage, 2005). These findings suggest that perhaps the difficulties associated with speech and language impairments may put this subgroup of children at greater risk for experiencing bullying. Savage (2005) cautioned that this theory may not be completely valid, as there may be specific social factors in a segregated classroom that make students 
more vulnerable to being victimized.

\section{Summary}

Of the studies reviewed, many had conflicting results. According to Cooney and colleagues (2006), students who are mainstreamed are often more likely to encounter victimization. On the other hand, Norwich and Kelly (2004) discovered that even if students with disabilities attend school in a separate setting, they still experience victimization in their neighborhood and by students attending other schools. Other research (e.g., Yude et al., 1998; Nadeau \& Tessier, 2006) indicates that students with physical disabilities are more prone to victimization due to the physically salient aspects of their disability. And, children with disabilities marked by social skills deficits, such as autism or even learning disabilities, may be more vulnerable to peer rejection and victimization (Orsmond et al., 2004; Kaukiainen et al., 2002). Children receiving resource help for speech-language difficulties may also be more likely to experience victimization, perhaps due to their communication difficulties (Savage, 2005).

Reviewed literature indicates that a child's specific disability status may influence the overall likelihood of experiencing peer rejection and/or victimization. Many factors, including age, gender, severity of disability, seem to influence the likelihood of becoming a victim. Future research should focus on the broad definition of disability and how it relates to peer relationships, which can ultimately influence risk for rejection and victimization. Many conflicting findings result when evaluating specific disabilities, suggesting that it may be more beneficial to look at disabilities from a broader perspective. 


\section{Students with Disabilities' Perceptions of Their Peers}

While much research has been conducted on how students with disabilities perceive their own social hierarchy in the school setting, there is an absence of work investigating how students with disabilities perceive their peers. Rodkin et al. (2006) asked students with mild

disabilities in fourth, fifth, and sixth grade to nominate peers in their mainstream classes that they perceived as being cool. Rodkin and colleagues (2006) theorized that this information could give insight on the social benefits of inclusion and mainstreaming. That is, would disabled children have positive peer role models or would they idolize peers with antisocial behaviors, indicating vulnerability for being influenced by negative role models. Based on their results, children who were nominated as cool by students with mild disabilities were viewed by the majority of all students as being a leader, athletic, and prosocial. Interestingly, there was a tendency for the students with mild disabilities to nominate peers who associated with the mildly disabled students as being cool (Rodkin et al., 2006). When social connections and centrality were taken into consideration, significant gender differences emerged. Males with mild disabilities who possessed high levels of social connectedness were more likely to view aggressive males as being cool, indicating that males with mild disabilities who are well integrated into their school's social network may be more at-risk when it comes to modeling aggressive behavior (Rodkin et al., 2006). 


\section{CHAPTER 3}

\section{SUMMARY, PURPOSE, AND RESEARCH QUESTIONS}

Overall, students with disabilities tend to report fewer friendships and supportive peers, as well as higher levels of victimization, than their non-disabled peers. Also, bullying tends to become more problematic as children develop and enter middle and high school. Many studies of victimization and peer relationships (i.e., Yude et al., 1998, Cooney et al, 1996, Dyson, 2005, etc.) have focused their attention on older students who are in middle and high school or younger students in preschool and kindergarten. More research is needed on students who are in the upper levels of elementary school, such as third to fifth grade, in order to better understand the quality of peer relationships at this age range. Children in this age range are unique in the sense that they are becoming more aware of their social world and are also preparing for the transition to middle school. Eccles, Wigfield, and Schiefele (1998) found that middle schools tend to disregard the formation of new cooperative peer relationships, which can increase the number of non-cohesive social groups since many students are trying to adjust to larger school buildings and environments that emphasize competition rather than collaboration (Pellegrini \& Long, 2004).

There has been little to no research conducted to investigate the relation between special education classification and reported protective peer relationships. The two aims of this paper are to compare the levels of protective peer relationships in children with and 
without disabilities and to determine if gender moderates protective peer relationships. The overarching goal of this paper is to address two research questions:

1. Do children with disabilities experience fewer protective peer relationships than their non-disabled peers?

It is hypothesized that children with disabilities will be less likely to experience protective peer relationships compared to their non-disabled peers. Previous research (e.g., Whitney, Smith, \& Thompson) has suggested that children with disabilities are more likely to be bullied than their non-disabled peers. If they are more likely to be bullied, it is assumed that they would be less likely to experience protection from bullying.

2. Does gender play a role in the levels of protective peer relationships reported by students with disabilities?

It is hypothesized that females with disabilities will experience fewer protective peer relationships than males with disabilities, as they may be less likely than males to have a same-sex peer with a similar disability. This hypothesis builds on the fact that males comprise 2/3 of the Exceptional Children population (U.S. Department of Education, 2005).

This research is important because it can assist in the future development of more appropriate bullying interventions and programs for children with disabilities. 


\section{CHAPTER 4}

\section{METHODS}

\section{Description of Larger Study}

This study examined existing data from a larger study (Song \& Siegel, 2006), which was a cross-sectional, correlational study. Active written parental consent was obtained from parents and child assent was obtained from students. Teachers from 27 classrooms in two elementary schools in a Midwestern School District were invited to participate in the study by consent letter, and all teachers consented. Four hundred third through fifth grade students from these classrooms were then asked to participate in the study, and parents of 299 students ( $75 \%$ of those invited) consented to their child's participation. All of these students assented to participate. A priori exclusionary criteria included insufficient knowledge of the English language, but no students were excluded based on this criterion.

\section{Procedures}

Student and teacher questionnaires were administered for the primary variables of interest in this study in addition to other variables that were part of a larger study. For the student assessment, measures assessing protective peers, peer protection, being bullied, and positive peer relationships were collected. Students gathered in a group based on their grade in either a computer room or cafeteria. A definition of bullying was described to students by the researcher prior to their completing the Protective Peer Ecology scale. All measures were read aloud to the students as a group by the researcher. In addition, the measures and their 
items were projected on a screen for the students to follow along, if needed. Additional research assistants and school personnel were available to answer any student questions. No students required accommodations because of reading or language difficulties. Upon completion, students were given a decorated pencil for their participation.

\section{Participants}

In this study, data for a total of 299 third (37\%), fourth (29\%), and fifth (34\%) graders between the ages of 8 and 11 were examined. Based on school records, $90 \%$ were European-American, 53\% were female, $47 \%$ were male, $27 \%$ received free and reduced lunch, and 14\% were identified for Exceptional Children services (i.e., disability status).

\section{Instruments}

Protective peer relationships were assessed by using the 9-item self-report Protective Peer Ecology Scale (Song, 2004). This scale utilizes 3-point Likert scaling, with a score of 1 indicating that no protective peer relationships exist and a score of 3 indicating high levels of protective peer relationships. A score of 2 indicated that protective peer relationships were sometimes, but not always, available. The Protective Peer Ecology Scale measures a child's belief about the degree of protection from bullying received by classmates (e.g., "stick up for me"). Prior studies (Song \& Siegel, 2006) have demonstrated a strong unidimensional structure, strong internal consistency (coefficient alpha $=.87$ ), and theoretically consistent relations with similar and different factors that were assessed concurrently. Because this is a self-report scale, the child participants read the items to themselves or they received assistance from one of the data collectors. 


\section{CHAPTER 5}

\section{RESULTS}

Analysis

Data were analyzed using an analysis of variance (ANOVA) method to evaluate the relationship between reported protective peer relationships and disability status. The Statistical Package for the Social Sciences (SPSS), Version 13.0 was employed for this analysis (SPSS Inc., Chicago IL). Generally speaking, the ANOVA method is useful in comparing differences between groups. For this paper, using an ANOVA method allowed for the comparison of two groups of students - those with disabilities and those who do not have a disability — on levels of protective peer relationships. Furthermore, gender and disability status and their relationship to protective peer relationships were investigated through the use of ANOVA. Preliminary analysis of the data indicated that the assumptions of ANOVA were met (i.e., homogeneity of variance).

The means and standard deviations for protective peer relationships as a function of gender and disability status are reported in Table 1, located on the following page. It is important to note that cell size were unequal, due to an unequal numbers of male and female participants. Further, only 37 , or approximately $14 \%$, of the 271 participants were identified as receiving Exceptional Children services. However, because children receiving Exceptional Children services make up a small portion of the entire student body population, these unequal cell sizes simply reflect the state of the Exceptional Children population. 
Table 1.

Means and standard deviations for protective peer relationships as function of gender and disability status

\begin{tabular}{lcccc} 
Gender & Disability status & Mean & Standard deviation & N \\
\hline Male & & & & 23 \\
& Yes & 1.91 & .58 & 105 \\
Female & No & 2.20 & .53 & 128 \\
& Total & 2.15 & .55 & 14 \\
& Yes & 2.51 & .40 & 129 \\
Total & No & 2.36 & .43 & 143 \\
& Total & 2.37 & .43 & 37 \\
& Yes & 2.14 & .59 & 234 \\
& No & 2.28 & .48 & 271 \\
\hline
\end{tabular}

Based on the figures presented in Table 1, it appears as though females with disabilities $(M=2.51)$ report greater levels of protective peer relationships than females without disabilities $(M=2.36)$. This finding was reversed for males, with fewer protective peer relationships being reported by males with disabilities $(M=1.91)$ versus males without disabilities $(M=2.20)$. These findings warrant further follow-up by ANOVA to determine whether these differences are statistically significant. Results from such analysis are provided on the following pages.

In addition to comparing means based on gender and disability status, it may be beneficial to briefly examine the role that grade level plays in the probability of experiencing protective peer relationships. Means and standard deviations as a function of grade level, gender, and disability status are presented in Table 2 , located on the following page. 
Table 2.

Means and standard deviations for protective peer relationships as a function of grade level, gender, and disability status

\begin{tabular}{cccccc}
\hline Grade & Gender & $\begin{array}{c}\text { Disability } \\
\text { status }\end{array}$ & Mean & $\begin{array}{c}\text { Standard } \\
\text { deviation }\end{array}$ & N \\
\hline $3^{\text {rd }}$ & Male & Yes & 1.86 & .60 & 8 \\
& & No & 2.24 & .47 & 41 \\
& & Total & 2.18 & .51 & 49 \\
& Female & Yes & 2.60 & .24 & 6 \\
& & No & 2.50 & .33 & 45 \\
& & Total & 2.51 & .32 & 51 \\
$4^{\text {th }}$ & Male & Yes & 2.04 & .74 & 6 \\
& & No & 2.16 & .49 & 29 \\
& & Total & 2.14 & .53 & 35 \\
& \multirow{4}{*}{ Female } & Yes & 2.56 & .38 & 6 \\
& & No & 2.31 & .35 & 39 \\
& & Total & 2.35 & .36 & 45 \\
$5^{\text {th }}$ & Male & Yes & 1.88 & .51 & 9 \\
& & No & 2.18 & .64 & 35 \\
& & Total & 2.12 & .62 & 44 \\
& & Yes & 2.06 & .80 & 2 \\
& & No & 2.25 & .54 & 45 \\
& & Total & 2.24 & .54 & 47 \\
\hline
\end{tabular}

The figures in Table 2 indicate that all females, regardless of disability status, reported experiencing decreased levels of protective peer relationships as they progress from $3^{\text {rd }}$ to $5^{\text {th }}$ grade. A different trend is seen in males. Fourth grade male participants with disabilities reported experiencing higher levels of protective peer relationships than males with disabilities enrolled in $3^{\text {rd }}$ and $5^{\text {th }}$ grade. Males without disabilities reported the highest levels of protective peer relationships when enrolled in $3^{\text {rd }}$ grade and the lowest levels of protective peer relationships in $4^{\text {th }}$ grade. These means should be interpreted with caution, though, since this is not a longitudinal study. Therefore, it is impossible to measure changes in protective peer relationships experienced by this particular group of participants as they progressed through the upper-elementary years. 
Research Question \#1: Do children with disabilities experience fewer protective peer relationships than their non-disabled peers?

A one-way ANOVA was conducted to evaluate the relation between disability status and self-reported levels of protective peer relationships. The independent variable, disability status, included two levels: whether or not the child received special education services. The dependent variable was the reported levels of protective peer relationships, as measured by the Protective Peers Ecology Scale (Song, 2004). The results of this one-way ANOVA indicated no significant relationship between disability status and protective peer relationships levels, $F(1,269)=2.725, p>.05$, although students with disabilities reported slightly lower levels of protective peer relationships $(M=2.14, S D=.60)$ than their nondisabled peers $(M=2.28, S D=.48)$. In addition, the strength of relationship, as assessed by $\eta^{2}$, between the independent and dependent variable was weak, with disability status accounting for only $1 \%$ of the variance in levels of protective peer relationships. These results are presented in detail in Table 3 on the following page. 
Table 3.

One-way ANOVA results for comparing protective peer relationships among students with and without disabilities

\begin{tabular}{|c|c|c|c|c|c|c|}
\hline Source & $\begin{array}{l}\text { Type III } \\
\text { Sum of } \\
\text { Squares }\end{array}$ & $\mathrm{df}$ & $\begin{array}{l}\text { Mean } \\
\text { Square }\end{array}$ & $\mathrm{F}$ & Sig. & $\begin{array}{c}\text { Partial Eta } \\
\text { Squared }\end{array}$ \\
\hline $\begin{array}{l}\text { Corrected } \\
\text { Model }\end{array}$ & $.683^{\mathrm{a}}$ & 1 & .683 & 2.725 & .100 & .010 \\
\hline Intercept & 625.070 & 1 & 625.070 & 2494.187 & .000 & .903 \\
\hline $\begin{array}{l}\text { Disability } \\
\text { Status }\end{array}$ & .683 & 1 & .683 & 2.725 & .100 & .010 \\
\hline Error & 67.414 & 269 & .251 & & & \\
\hline Total & 1458.094 & 271 & & & & \\
\hline $\begin{array}{l}\text { Corrected } \\
\text { Total }\end{array}$ & 68.097 & 270 & & & & \\
\hline
\end{tabular}

Research Question \#2: Does gender play a role in the levels of protective peer relationships reported by students with disabilities?

To compare gender differences and disability status in relation to levels of protective peer relationships, a two-way ANOVA was employed. Specifically, a 2 X 2 ANOVA was conducted to evaluate the effects of gender and disability status on reported levels of protective peer relationships. The results for the ANOVA indicated a significant main effect for gender, $F(1,267)=18.258, p<.01$, partial $\eta^{2}=.064$, and a nonsignificant main effect for disability status, $F(1,267)=.554, p=.458$, partial $\eta^{2}=.002$. There was a significant interaction between gender and disability status on reported levels of protective peer relationships, $F(1,267)=6.160, p<.05$, partial $\eta^{2}=.023$. By looking at both the previously calculated means and the results of the 2 X 2 ANOVA, it is evident that females with disabilities were significantly more likely to report receiving protective peer relationships $(M$ 
$=2.51, S D=.40)$ than males with disabilities $(M=1.91, S D=.58), F(1,267)=18.258, p<$ .01. Detailed results of the 2 X 2 ANOVA can be found in Table 4 below.

Table 4.

Two-way ANOVA results for comparing protective peer relationships based on gender and disability status

\begin{tabular}{lcccccc}
\hline Source & $\begin{array}{c}\text { Type III } \\
\text { Sum of } \\
\text { Squares }\end{array}$ & df & $\begin{array}{l}\text { Mean } \\
\text { Square }\end{array}$ & F & Sig. & $\begin{array}{c}\text { Partial Eta } \\
\text { Squared }\end{array}$ \\
\hline $\begin{array}{l}\text { Corrected } \\
\text { Model }\end{array}$ & $5.218^{\mathrm{a}}$ & 3 & 1.739 & 7.386 & .000 & .077 \\
Intercept & 609.418 & 1 & 609.418 & 2587.739 & .000 & .906 \\
Gender & 4.300 & 1 & 4.300 & 18.258 & .000 & .064 \\
$\begin{array}{l}\text { Disability } \\
\text { status }\end{array}$ & .130 & 1 & .130 & .554 & .458 & .002 \\
$\begin{array}{l}\text { Gender } \mathrm{x} \\
\text { Disability }\end{array}$ & 1.451 & 1 & 1.451 & 6.160 & .014 & .023 \\
status & & & & & & \\
Error & 62.879 & 267 & .236 & & & \\
Total & 1458.094 & 271 & & & & \\
$\begin{array}{l}\text { Corrected } \\
\text { Total }\end{array}$ & 68.097 & 270 & & & & \\
\hline a. R squared $=.077$ (Adjusted R Squared $=.006)$ & & & &
\end{tabular}

Although a significant main effect emerged for gender, there is no need to conduct a follow-up of this significant main effect since gender is only comprised of two levels, male and female. The main effect associated with gender indicates that there are significant differences in the levels of protective peer relationships reported by female and male participants. No further analyses are needed to evaluate the significant main effect for gender. As previously stated, a significant interaction emerged between gender and disability status. Because there are fewer than three groups for gender (only male and female) and disability status (either yes or no), post hoc tests cannot be conducted on this particular data set. By simply looking at the means, though, it is apparent that females with disabilities 
report significantly higher levels of protective peer relationships than males with disabilities.

Overall, these results indicate that males with disabilities are significantly less likely to experience protective peer relationships in comparison to females with disabilities. Concerning the second research question, female participants with disabilities were more likely to experience protective peer relationships than males with disabilities. Based on mean scores, elementary-age females with disabilities reported higher levels of protective peer relationships than their non-disabled female peers. And, females with disabilities were significantly more likely to report experiencing protective peer relationships during instances of bullying than males with disabilities. 


\section{CHAPTER 6}

\section{DISCUSSION}

In this paper, data were analyzed through the use of ANOVA to answer the two relevant research questions:

1. Do children with disabilities experience fewer protective peer relationships than their non-disabled peers?

2. Does gender play a role in the levels of protective peer relationships reported by students with disabilities?

Regarding the first research question, results of the data analysis indicated that there was no significant relation between disability status and levels of protective peer relationships in the $3^{\text {rd }}$ to $5^{\text {th }}$ grade student participants. This finding was contrary to the first hypothesis. Still, despite the lack of a significant relationship, students with disabilities reported slightly fewer protective peer relationships than their non-disabled peers.

Regarding the second research question, the 2 X 2 ANOVA indicated that participating females with disabilities were significantly more likely to experience protective peer relationships than participating males with disabilities. This finding was also contrary to the second hypothesis. Interestingly, females with disabilities reported higher levels of protective peer relationships than non-disabled females. And, males, regardless of disability status, experienced fewer protective peer relationships in comparison to females. 


\section{Disability Status and Protective Peer Relationships}

Surprisingly, no significant differences were found in the levels of protective peer relationships experienced by students with and without disabilities. For the purpose of this study, specific disability status was not taken into account, which may help explain this unexpected finding. Instead, a broader category (i.e., Exceptional Children eligibility) was used to determine disability status. It has been suggested (Odom et al., 2006) that children with specific disabilities, such as autism, mental retardation, and behavioral disturbances, may be less competent socially, which in turn leads to peer rejection. Children with disabilities that do not result in great social impairment, such as speech-language impairment or learning disability, may experience levels of social acceptance comparable to students without disabilities. For this study, individual disability status of student participants was not established, therefore rendering it impossible to determine the impact that a specific disability status has on one's quantity of protective peer relationships.

\section{Gender, Disability Status, and Protective Peer Relationships}

These findings support previous research that has suggested that significant gender differences exist regarding friendship (e.g., Cunningham, Thomas, \& Warschausky, 2007). Broadly speaking, females tend to be more nurturing in their relationships, which may explain why they are more likely to experience protective peer relationships (Gilligan, 1982). Because females tend to be more nurturing, and perhaps even more empathetic, they may be more willing to defend a female peer who is being bullied. Additionally, females often have stronger relationships than males, with an emphasis placed on companionship, help, security, and closeness (Cunningham et al., 2007). They also tend to be more supportive and loyal 
than males (Cunningham et al., 2007). Males, on the other hand, are more likely to seek independence and competition in their friendships (Cunningham et al., 2007).

Salmivalli and colleagues ascertained the gender differences in sixth-grade students who were willing to serve as a defender of a bullying victim (Salmivalli, Lagerspetz, Bjorkqvist, Osterman, Kaukiainen, 1996). Results of their study indicated that more females (30.1\%) served as bullying defenders than males (4.5\%) (Salmivalli et al., 1996). Because females are expected to behave in a prosocial and care-taking manner, those expectations may ultimately influence their decision to defend peers who are being victimized (Salmivalli et al., 1996). Salmivalli's research may help to explain why female participants in this current study were more likely to report experiencing protective peer relationships than males without disabilities, simply because they may have a greater number of female friends compared to the number of female friends that males may have.

Based on both current research and review of previous research, males emphasize sticking up for oneself instead of seeking assistance from peers. Females, on the other hand, tend to be more nurturing, and are more likely to defend peers who are being bullied (Salmivalli et al., 1996). These gender differences could explain why males in the participant group were significantly less likely to experience protective peer relationships than the female participants, regardless of disability status.

\section{Limitations}

Several limitations existed for this study. First, as mentioned previously, a significant limitation of this study is that it failed to take into account specific disability status. Odom 
and colleagues (2006) found that when children had disabilities characterized by deficits in social problem solving and emotional regulation, they were more likely to experience peer rejection. For this paper, disability status was a simple binary category, which did not allow for more complex and sensitive methods of measuring disability. Because the sample used for this paper does not allow for the comparison of specific disability status to overall levels of protective peer relationships, it is impossible to ascertain whether or not a specific disability results in fewer or greater numbers of protective peer relationships.

Second, the sample was relatively small, especially within each grade, and consisted of a homogeneous population. The majority of the student participants were of EuropeanAmerican descent. Therefore, the results of this research would not be generalizable to more diverse school populations.

Third, a self-report scale was utilized to gain further understanding into the relationship between gender, disability status, and levels of protective peer relationships. Due to the nature of self-report measures, the student participants may not have been truthful or they may have had difficulty comprehending the provided questions even if they received assistance from a data collector. Further, the use of self-report scales may result in problems involving shared method variance.

Additionally, because this is the first study to examine the protective peer relationships reported by students with disabilities, it is important to interpret these findings with caution. It is important that these findings be replicated in future studies so that the results will have more merit. 


\section{Future Research}

Results of this current research indicate that males, regardless of disability status, are less likely to experience protective peer relationships. Notably, females who were identified as receiving Exceptional Children services were more likely to experience protective peer relationships than females who were not identified for special services. In the future, it would be beneficial to incorporate multiple informant methods to measure protective peer relationships while simultaneously using more sophisticated methods to ascertain disability status. The use of more sophisticated data collection techniques may yield further insight into why females with disabilities experience more protective peer relationships than typically-developing females and why males, in general, experience fewer protective peer relationships. Finally, this study should be replicated with a larger and more diverse population in order to yield more generalizable results. 


\section{REFERENCES}

Boutot, E. A., \& Bryant, D. P. (2005). Social Integration of Students with Autism in Inclusive Settings. Education and Training in Developmental Disabilities, 40(1), 1423.

Cooney, G., Jahoda, A., Gumley, A., \& Knott, F. (2006). Young people with intellectual disabilities attending mainstream and segregated schooling: perceived stigma, social comparison and future aspirations. Journal of Intellectual Disability Research, 50(6), 432-444.

Doll, B., Zucker, S., \& Brehm, K. (2004). Resilient classrooms: Creating healthy environments for learning. New York: Guilford.

Doren, B., Bullis, M., \& Benz, M. R. (1996). Predictors of Victimization Experiences of Adolescents with Disabilities in Transition. Exceptional Children, 63(1), 7-18.

Dyson, L. L. (2005). Kindergarten Children's Understanding of and Attitudes Toward People With Disabilities. Topics in Early Childhood Special Education, 25(2), $95-$ 105.

Flynt, S. W., \& Morton, R. C. (2004). Bullying and Children with Disabilities. Journal of Instructional Psychology, 31(4), 330-333.

Fox, C. L, \& Boulton, M. J. (2006). Friendship as a Moderator of the Relationship Between Social Skills Problems and Peer Victimization. Aggressive Behavior, 32, 110-121.

Gilligan, C. (1982). In a Different Voice: Psychological Theory and Women's Development. Cambridge, MA: Harvard University Press.

Hall, L. J., \& McGregor, J. A. (2000). A Follow-Up Study of the Peer Relationships of Children with Disabilities in an Inclusive School. The Journal of Special Education, 34(3), 114-126.

Hodges, E. V. E., Boivin, M., \& Vitaro, F. (1999). The power of friendship: Protection against an escalating cycle of peer victimization. Developmental Psychology, 35(1), 94-101.

Individuals with Disabilities Education Improvement Act, 20 U.S.C. § 1412 (2004).

Johnson, D. W., Johnson, R. T., Buckman, L. A., \& Richards, P. S. (1985). The effect of prolonged implementation of cooperative learning on social support within the classroom. Journal of Psychology, 119, 405-411. 
Kaukiainen, A., Salmivalli, C., Lagerspetz, K., Tamminen, M., Vauras, M., Maki, H., \& Poskiparta, E. (2002). Learning difficulties, social intelligence, and self-concept: Connections to bully-victim problems. Scandinavian Journal of Psychology, 43, 269278.

Kochenderfer, B. J., \& Ladd, G. W. (1996). Peer victimization: Cause or consequence of children's school adjustment difficulties? Child Development, 67, 1305-1317.

Least Restrictive Environment Coalition: Benefits of LRE. (n.d.). Retrieved November 5, 2006, from http://www.lrecolaition.org/04_benefitsOfLRE/index.htm\#ben

Nadeau, L., \& Tessier, R. (2006). Social adjustment of children with cerebral palsy in mainstream classes: peer perception. Developmental Medicine and Child Neurology, 48, 331-336.

National Center for Education Statistics. (2003). Digest of Education Statistics and Number, 2003. Retrieved October 10, 2006, from http://nces.ed.gov/programs/digest/d03/tables/dt054.asp

Norwich, B., \& Kelly, N. (2004). Pupils' views on inclusion: moderate learning difficulties and bullying in mainstream and special schools. British Educational Research Journal, 30(1), 43-65.

Odom, S.L., Zercher, C., Li, S., Marquart, J.M., Sandall, S., \& Brown, W.H. (2006). Social Acceptance and Rejection of Preschool Children With Disabilities: A Mixed-Method Analysis. Journal of Educational Psychology, 98(4), 807-823.

Orsmond, G. I., Krauss, M. W., \& Seltzer, M. M. (2004). Peer Relationships and Social and Recreational Activities Among Adolescents and Adults with Autism. Journal of Autism and Developmental Disorders, 34(3), 245-256.

Pellegrini, A. D., \& Long, J. D. (2004). Part of the Solution and Part of the Problem: The Role of Peers in Bullying, Dominance, and Victimization During the Transition From Primary School Through Secondary School. In D. L. Espelage \& S. M. Swearer (Eds.), Bullying in American Schools: A Social-Ecological Perspective on Prevention and Intervention (pp. 107-117). Mahwah, New Jersey: Lawrence Erlbaum Associates.

Rodkin, P. C., Farmer, T. W., Van Acker, R., Pearl, R., Thompson, J. H., \& Fedora, P. (2006). Who do students with mild disabilities nominate as cool in inclusive general education classrooms? Journal of School Psychology, 44, 67-84. 
Rubin, K. H., Dwyer, K. M., Booth-LaForce, C., Kim, A. H., Burgess, K. B., \& RoseKrasnor, L. (2004). Attachment, Friendship, and Psychosocial Functioning in Early Adolescence. Journal of Early Adolescence, 24(4), 326-356.

Salmivalli, C., Lagerspetz, K., Bjorkqvist, K., Osterman, K., \& Kaukiainen, A. (1996). Bullying as a Group Process: Participant Roles and Their Relations to Social Status Within the Group. Aggressive Behavior, 22, 1-15.

Savage, R. (2005). Friendship and Bullying Patterns in Children Attending a Language Base in a Mainstream School. Educational Psychology in Practice, 21(1), 23-36.

Skar, L. (2003). Peer and adult relationships of adolescents with disabilities. Journal of Adolescence, 26, 653-649.

SPSS Inc. (2005). SPSS Base 13.0 for Windows User's Guide. SPSS Inc., Chicago IL.

Song, S. Y. (2004). Protective Peer Ecology Scale. Unpublished measure.

Song, S.Y., Doll, B., Swearer, S.M., \& Johnsen, L. (2005). Understanding the Role of the Peer Ecology in Bullying Prevention. Paper presented at the 2005 Annual Convention of the National Association of School Psychologists, Atlanta, GA.

Song, S.Y., \& Siegel, N. (2006, May). The Need to Consider Protective Peers for School Bullying Prevention: Psychometric Properties of the Protective Peer Ecology Scale. Original research paper published in the Conference Proceedings of the Korean School Psychological Association, May 2006, Republic of Korea.

Song, S.Y. \& Stoiber, K. (in press). Children Exposed to Violence at School: Understanding Bullying and Evidence-based Interventions. Special issue on Children Exposed to Violence, Journal of Emotional Abuse, 20 pages.

Tamm, M., \& Prellwitz, M. (2001). 'If I had a friend in a wheelchair': children's thoughts on disabilities. Child: Care, Health, and Development, 27(3), 223-240.

Thompson, D., Whitney, I., \& Smith, P.K. (1994). Bullying of Children with Special Needs in Mainstream Schools. Support for Learning, 9(3), 103-106.

United States Department of Education. (2005). 25 th Annual Report to Congress on the Implementation of the Individuals with Disabilities Education Act. Retrieved November 5, 2006 from http://www.ed.gov/about/reports/annual/osep/2003/index.html

Vaughn, S., Elbaum, B. E., Schumm, J. S., \& Hughes, M. T. (1998). Social Outcomes for Students With and Without Learning Disabilities in Inclusive Classrooms. Journal of Learning Disabilities, 31(5), 428-436. 
Yude, C., Goodman, R., \& McConachie, H. (1998). Peer Problems of Children with Hemiplegia in Mainstream Primary Schools. Journal of Child Psychology and Psychiatry, 39(4), 553-541. 